\title{
Haemoconcentration risk at the end of pregnancy: effects on neonatal behaviour
}

\author{
Nuria Aranda ${ }^{1,4} \uparrow$, Carmen Hernández-Martínez ${ }^{2,4} \uparrow$, Victoria Arija ${ }^{1,3,4}$, Blanca Ribot ${ }^{1,4}$ \\ and Josefa Canals ${ }^{2,4, *}$ \\ ${ }^{1}$ Nutrition and Public Health Unit, Faculty of Medicine and Health Sciences, Universitat Rovira i Virgili, Reus, Spain: \\ ${ }^{2}$ Department of Psychology, Faculty of Educational Sciences and Psychology, Universitat Rovira i Virgili, Ctra. Valls \\ s/n, 43007 Tarragona, Spain: ${ }^{3}$ Unitat de Suport a la Recerca Tarragona-Reus, Institut Universitari d'Investigació en \\ Atenció Primària Jordi Gol, Tarragona, Spain: ${ }^{4}$ Research Group in Nutrition and Mental Health (NUTRISAM), Institut \\ d'Investigació Sanitària Pere Virgili (IISPV), Universitat Rovira i Virgili, Reus, Spain
}

Submitted 31 May 2016: Final revision received 7 December 2016: Accepted 13 December 2016: First published online 6 February 2017

\begin{abstract}
Objective: To determine the associations between haemoconcentration at the end of pregnancy (third trimester and delivery) and neonatal behaviour in healthy pregnant women supplemented with moderate doses of Fe.

Design: A prospective longitudinal study in which obstetric and clinical history, maternal toxic habits, maternal anxiety and $\mathrm{Hb}$ levels were recorded at the third trimester and delivery. Neonatal behaviour was assessed at 48-72 h of age using the Neonatal Behavioral Assessment Scale.

Setting: Unit of Obstetrics and Gynaecology of the Sant Joan University Hospital in Reus, Tarragona (Spain).

Subjects: A total of 210 healthy and well-nourished pregnant women and their full-term, normal-weight newborns.

Results: The results showed that, after adjusting for confounders, in the third trimester the risk of haemoconcentration ( $6.2 \%$ of pregnant women) was related to decreased neonatal state regulation $(B=-1 \cdot 273, P=0 \cdot 006)$ and alertness $(B=-1 \cdot 848, P=0 \cdot 006)$ scores. In addition, the risk of haemoconcentration at delivery $(12.0 \%$ of pregnant women) was also related to decreased neonatal state regulation $(B=-0.796$, $P=0.021)$ and poor robustness and endurance $(B=-0.921, P=0.005)$ scores.

Conclusions: Our results show that the risk of haemoconcentration at the end of pregnancy is related to the neonate's neurodevelopment (and self-regulation capabilities), suggesting that Fe supplementation patterns and maternal Fe status during pregnancy are important factors for neurodevelopment which may be carefully controlled.
\end{abstract}

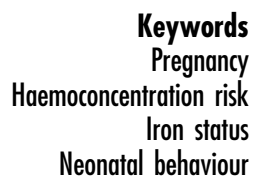

In recent years, various studies have investigated prenatal Fe status and its effects on maternal and fetal health. It is well established that Fe deficiency (ID) is highly prevalent during pregnancy (18-40\%) in both developing and developed countries ${ }^{(1)}$ and is related to adverse obstetric outcomes such as low birth weight, preterm delivery ${ }^{(2-6)}$ and behavioural, emotional and cognitive outcomes throughout infant development ${ }^{(7-10)}$. This is because, during fetal development, $\mathrm{Fe}$ is essential for $\mathrm{Hb}$ synthesis and is an important factor in neuronal synapse formation, myelination and the synthesis of certain neurotransmitters in the central nervous system (CNS) ${ }^{(11)}$.

To prevent ID during pregnancy, several countries have launched generalized and routine $\mathrm{Fe}$ supplementation

$\dagger$ These authors contributed equally to this work. programmes. Most of these are generally beneficial to maternal-fetal health but, in some cases, they may contribute to increased $\mathrm{Fe}$ and $\mathrm{Hb}$ levels and thus lead to haemoconcentration ${ }^{(12)}$. Because this condition is less prevalent $(13 \cdot 3 \%)^{(13,14)}$, its effects are less studied.

High ferritin levels have been related to oxidative stress $^{(2,15-18)}$ and to reduced absorption of other important minerals ${ }^{(19)}$, and haemoconcentration has been related to increased blood viscosity and blood pressure ${ }^{(20)}$, which impedes the placental-fetal blood flow and interferes with the fetal supply of oxygen and nutrients ${ }^{(21,22)}$. All of these conditions may interfere during the course of pregnancy with the general development of the fetus and the development of its CNS. In fact, high Fe levels and haemoconcentration have been related to premature birth and low birth weight ${ }^{(13,14,20,21,23-25)}$ but there are few 
studies that have related these conditions with neurodevelopmental outcomes. The CNS is the most complex and vulnerable organ in the human body and its development is also correspondingly an extremely complex and vulnerable period $^{(26)}$. This process is largely dependent on the appropriate release of oxygen, protein, energy and micronutrients, and an inadequate supply of these may contribute to alterations in neurodevelopment ${ }^{(27)}$. Tamura et $a l .{ }^{(28)}$ studied the relationship between cord ferritin concentrations and cognitive development and found that infants with cord ferritin levels in the highest quartile showed lower IQ (intelligence quotient) scores at 5 years old. Those authors attributed these results to possible maternal infections or neuronal damage caused by oxidative stress resulting from Fe overload. In relation to the amount of Fe supplementation, the study by Hanieh et $a l .{ }^{(29)}$ compared a daily $\mathrm{Fe}$ supplementation pattern with a twice weekly Fe supplementation pattern and found that children of mothers with a daily Fe supplementation pattern scored lower in a cognitive test at 6 months old; in fact, $40 \%$ of women with this pattern of supplementation were found to have ferritin levels greater than $41 \mu \mathrm{g} / 1$ and normal $\mathrm{Hb}$ concentrations, results that were attributed to oxidative stress processes related to high Fe levels. There are certain aspects of these studies that deserve special attention. First, their main aims were to examine the effects on different levels of ID (serum cord ferritin, $\mathrm{Hb}$ concentrations), which meant that they paid little attention to results related to elevated ferritin or high $\mathrm{Hb}$ concentrations. Second, cognitive development was assessed at 4 months and 4-6 years old, ages at which other multiple factors can also affect infant cognitive development, including maternal education and psychopathology, obstetric conditions, mother-infant attachment, infant breast-feeding, educational programmes, genetic factors, nutritional status, etc. ${ }^{(30-35)}$. Third, the infant's own Fe status also affects her/his cognitive development ${ }^{(36)}$ and this variable was not taken into account. Consequently, to study the long-term effects of pregnancy $\mathrm{Hb}$ concentrations, several variables must be taken into account. However, neonatal behavioural characteristics shortly after birth are not influenced by these longer-term postnatal variables, although prenatal conditions must be also taken into account. Several studies have shown that prenatal maternal toxic habits, socio-economic status and anxiety, among other factors, are related to neonatal behaviour $^{(30,31,33,37)}$, suggesting that relationships must be adjusted for them. To our knowledge, to date there are no data regarding the potentially harmful effect of high $\mathrm{Hb}$ levels on neurobehavioural development in newborns.

Another important issue is the moment during gestation at which these harmful conditions occur. As Georgieff suggested $^{(38)}$, the effect of any nutrient deficiency or overabundance on brain development will be governed by the principle of timing, dose and duration. In this regard, Hernández-Martínez et al. ${ }^{(10)}$ found that the effects of ID on CNS development varied depending on the trimester of pregnancy in which the ID occurred and depending on the level of ID. Although late pregnancy seems to be a vulnerable period for nutritional insults ${ }^{(8,39,40)}$, there are no studies that investigate whether the effect of elevated levels of Fe on neurodevelopment is different depending on the point during pregnancy when this condition occurs.

Given all this information, it is clear that further studies are needed on the possible effects of high $\mathrm{Hb}$ concentrations in pregnant women on newborn neurodevelopment. Consequently, the main aim of the present study was to assess the effects of haemoconcentration at the end of pregnancy on neonatal behaviour after controlling for confounding factors. We hypothesized that high $\mathrm{Hb}$ concentrations at the end of pregnancy will be related to poor neonatal development.

\section{Methods}

\section{Sample}

Participants were pregnant women followed from the first trimester of gestation to childbirth. These women were volunteers and the Unit of Obstetrics and Gynaecology of the Sant Joan University Hospital in Reus (Spain) carried the recruitment out over 4 years (from 2004 to 2008).

The inclusion criteria for the study were being a healthy pregnant Caucasian woman older than 18 years with a singleton pregnancy at gestational week $\leq 11$. Exclusion criteria applied across the duration of the study were: having a chronic illness or a possible inflammation (serum ferritin (SF) $>62 \mu \mathrm{g} / \mathrm{l}$ and transferrin saturation $<16 \%)^{(41,42)}$; having a multiple pregnancy; not meeting the prescribed Fe supplementation during pregnancy; not complying with the scheduled clinical visits; not having blood drawn at each clinical visit; and giving birth at another hospital.

A total of 299 well-nourished Spanish pregnant women were recruited, of which $27 \cdot 8 \%$ were excluded for fetal loss, having incomplete biochemical parameters or having gone to another hospital to give birth. In addition, of the 216 women, six had a possible inflammation that could alter biochemical parameters and were excluded. Hence, the final sample was composed of 210 mothers aged from 18 to 43 years and their neonates ( $47.6 \%$ boys and $52.4 \%$ girls). There were no significant differences in psychosocial and sociodemographic characteristics between the excluded and the included women. The statistical power of the results in terms of sample size, standard deviation from the Neonatal Behavioral Assessment Scale (NBAS) scores and the number of women with and without haemoconcentration risk at the end of pregnancy and partum is $87 \%$.

\section{Procedure and study design}

The present longitudinal study was conducted according to the guidelines laid down in the Declaration of Helsinki 
and all procedures involving pregnant women were approved by the Ethics Committee of the Sant Joan University Hospital in Reus. Women admitted to the study were recruited during their first prenatal care visit (at gestational week $\leq 11$ ) by gynaecologists from the Sant Joan University Hospital in Reus and written informed consent was obtained from all of them.

Study data were recorded during their pregnancy consultations. At week 10, consultation, clinical and obstetric histories were recorded, and blood samples were collected for laboratory analysis. At week 15, the obstetrician prescribed $40 \mathrm{mg} \mathrm{Fe} / \mathrm{d}$ in accordance with the study protocol and the guidelines of the Spanish Ministry of Health and Consumption ${ }^{(43)}$. This dose was adapted in the following clinical visits according to maternal $\mathrm{Hb}$ and SF levels. At 24 and 34 weeks, the clinical and obstetric histories were revised, blood samples were collected, and a member of research team (in a separate room to encourage true responses) carried out a semi-structured interview on adherence to the Fe supplementation. At delivery, blood samples were collected and obstetric and neonatal variables were recorded (gestational age, neonatal birth weight and gender). In the immediate postpartum period (between 48 and $72 \mathrm{~h}$ after delivery) retrospective maternal anxiety and neonatal behaviour were assessed by two trained examiners ( $\kappa$ accordance $0 \cdot 9$ ) in a room at the hospital with optimal conditions. The examination of the newborn was completed in 20-25 min and was carried out midway between feedings. Not all newborns could be scored on the habituation items because they did not achieve the optimal state of consciousness (state 1, 2 or 3).

\section{Measures}

$\mathrm{Hb}$ concentrations in the blood were measured immediately at the clinical visits using a Coulter GENS analyser (Coulter, Hialeah, FL, USA). Serum and plasma were stored at $-80^{\circ} \mathrm{C}$ in our biobank and thawed immediately prior to batch analyses to reduce inter-batch variation in analysis. SF was determined by turbidimetric immunoassay as described by Gomez et al. ${ }^{(44)}$. According to the WHO recommendations ${ }^{(45,46)}$, Hb values were codified into three categories: (a) anaemia $(\mathrm{Hb}<105 \mathrm{~g} / 1$ in the second trimester and $<110 \mathrm{~g} / \mathrm{l}$ in the third trimester and at delivery, and depleted Fe stores as SF $<12 \mu \mathrm{g} / \mathrm{l}$ ); (ii) normal ( $\mathrm{Hb}$ between 105 and $130 \mathrm{~g} / \mathrm{l}$ in the second trimester and between 110 and $130 \mathrm{~g} / 1$ in the third trimester); and (iii) risk of haemoconcentration $(\mathrm{Hb}>130 \mathrm{~g} / \mathrm{l})^{(24)}$.

Neonatal behaviour was assessed at $48-72 \mathrm{~h}$ of age using the Spanish translation of the NBAS ${ }^{(47)}$. The NBAS assesses the behaviour of the newborn within the dynamic context of the infant-caregiver relationship. The NBAS contains twenty-eight behavioural items scored for optimal performance on a 9-point scale (except for one item, 'smiles', for which the scoring criterion is to record the number of times a smile is observed during the exam); seven supplementary items, also scored on a 9-point scale; and eighteen reflex items that are designed to identify gross neurological abnormalities and which are scored on a 4-point scale. Behavioural items are classified into six clusters: (i) habituation, which evaluates the neonate's ability to respond to and inhibit discrete stimuli while asleep (four items); (ii) social-interactive, which evaluates the neonate's ability to attend to visual and auditory stimuli and the quality of overall alertness (seven items); (iii) the motor system, which evaluates neonate motor performance, quality of movement and muscular tone (five items); (iv) state organization, which evaluates infant arousal irritability and lability of states (four items); (v) state regulation, which evaluates the neonate's ability to regulate her/his state when faced with increasing levels of stimulation (four items); and (vi) the autonomic system, which records signs of stress related to homeostatic adjustments in the CNS (four items, 'smiles' included). The following supplementary items assess several aspects of overall infant behaviour during assessment: quality of alertness (assesses the infant attentional state), cost of attention (assesses the effort that the infant makes to keep an optimal state of alertness), examiner facilitation (assesses the effort that the examiner makes to help the infant to keep a good state of alertness), general irritability (assesses the infant reactions of irritability), robustness and endurance (assesses the general physical resistance), state regulation (assesses the infant general self-regulation capabilities) and examiner's emotional response (assesses the emotional response that the examiner feels during the examination).

Maternal anxiety was assessed using the Spanish version of the State Trait Anxiety Inventory (STAI) ${ }^{(48)}$. This self-report questionnaire contains forty items that assess state anxiety, which is the level of transient and situational anxiety; and trait anxiety, the level of dispositional and stable trait anxiety. For the present study, we used trait anxiety as a confounding variable.

The socio-economic level of the family was assessed using the Hollingshead Index ${ }^{(49)}$. This index estimates the individual's social status by grouping occupations into nine categories (from unskilled to highly skilled work) and by grouping the level of education into seven categories (from non-completed primary education to completed higher education). The status score is estimated by multiplying the occupation-scale value by 5 and the education-scale value by 3 and then combining the two scores.

\section{Statistical analysis}

All statistical analyses were carried out using the statistical software package IBM SPSS Statistics Version 22.0.

All variables were checked for normality of distribution. All variables were normally distributed, and are presented as percentages or as means and standard deviations.

The Bonferroni correction was applied to control for the increase in type I error due to multiple comparisons; the significance level was 0.025. 
ANOVA was performed to test the differences in neonatal behaviour between the different groups of Hb levels and a Bonferroni post hoc analysis was applied.

To study if the risk of haemoconcentration is a significant predictor of neonatal behaviour, unadjusted and adjusted multiple linear regression models were performed for each NBAS cluster and supplementary item, and for the third trimester and delivery. Prior to these analyses, collinearity between variables was checked and the collinear variables (maternal SF level, umbilical cord blood ferritin and gestational age at birth) were deleted from the analysis. The $\mathrm{Hb}$ level variable was transformed into two dummy variables (dummy 1: anaemia $v$. normal Hb levels; dummy 2: haemoconcentration risk $v$. normal $\mathrm{Hb}$ levels) for entry in the multiple linear regression. In the unadjusted multiple linear regression models, the entry method was used to introduce the $\mathrm{Hb}$ level variable, and in the adjusted models, the entry method was used to enter the $\mathrm{Hb}$ level variable and the stepwise method to enter the confounding variables. The candidate variables for entry in the models were: infant birth weight at delivery (grams); socio-economic status of the family (total score); prenatal tobacco smoke exposure (no, yes); infant gender (female, male); and prenatal anxiety maternal trait (total score).

\section{Results}

\section{Descriptive data of the sample}

The sample characteristics are shown in Table 1. In general, the socio-economic status of the families was medium-high (92\%) and the level of trait anxiety was moderate (mean 15.4 (SD 7.9)) in comparison to Spanish data. In relation to neonatal variables, the mean gestational age was 39.3 (SD 1.4) weeks and the mean birth weight was 3231.2 (sD $403 \cdot 7$ ) $\mathrm{g}$.

All the mothers included in the analysis systematically received Fe supplements from about week 15 and the mean pharmacological Fe supplementation was 43.9 (SD $26 \cdot 6) \mathrm{mg} / \mathrm{d}$. The prevalence of haemoconcentration risk in the third trimester was $6.2 \%$ and at delivery was $12.0 \%$. The prevalence of anaemia and low SF levels increased in the second and third trimesters. At delivery, 53.4 and $21.5 \%$ of women had low Fe stores and anaemia, respectively.

\section{Neonatal behaviour differences between Hb level groups at different stages of pregnancy}

Table 2 shows differences in NBAS clusters between groups of $\mathrm{Hb}$ levels in the third trimester of pregnancy and at delivery. The first and second trimesters were not included in the analyses due to the low number of women in the haemoconcentration risk group.

Children of mothers with higher levels of $\mathrm{Hb}(>130 \mathrm{~g} / \mathrm{l})$ in the third trimester scored significantly lower in the state
Table 1 Characteristics of the sample of healthy and wellnourished pregnant women and their full-term, normal-weight newborns (n 210), Reus, Spain, 2004-2008

\begin{tabular}{|c|c|c|}
\hline & Mean or \% & SD or $n$ \\
\hline \multicolumn{3}{|l|}{ Mothers } \\
\hline Age (years; mean and SD) & $31 \cdot 7$ & $4 \cdot 3$ \\
\hline \multicolumn{3}{|l|}{$\begin{array}{l}\text { Socio-economic status of the family } \\
(\% \text { and } n)\end{array}$} \\
\hline Low & $8 \cdot 0$ & 17 \\
\hline Medium & 47.5 & 100 \\
\hline High & 44.5 & 93 \\
\hline Smoker† (\% and $n)$ & $20 \cdot 0$ & 42 \\
\hline $\begin{array}{l}\text { Fe dose of supplementation }(\mathrm{mg} / \mathrm{d} \text {; mean } \\
\text { and SD) }\end{array}$ & $43 \cdot 9$ & $26 \cdot 6$ \\
\hline Trait anxiety score (mean and SD) & $15 \cdot 4$ & $7 \cdot 9$ \\
\hline \multicolumn{3}{|l|}{$\mathrm{Hb}$ level (g/l; mean and sD) } \\
\hline At week 10 & $125 \cdot 7$ & 8.0 \\
\hline At week 24 & $113 \cdot 1$ & $8 \cdot 6$ \\
\hline At week 34 & $114 \cdot 2$ & $9 \cdot 6$ \\
\hline At delivery & $116 \cdot 9$ & $10 \cdot 9$ \\
\hline \multicolumn{3}{|l|}{ Anaemia $(\%$ and $n)$} \\
\hline At week $10(\mathrm{Hb}<110 \mathrm{~g} / \mathrm{l})$ & $2 \cdot 9$ & 6 \\
\hline At week $24(\mathrm{Hb}<105 \mathrm{~g} / \mathrm{l})$ & 14.9 & 31 \\
\hline At week $34(\mathrm{Hb}<110 \mathrm{~g} / \mathrm{l})$ & $28 \cdot 2$ & 59 \\
\hline At delivery $(\mathrm{Hb}<110 \mathrm{~g} / \mathrm{l})$ & 21.5 & 45 \\
\hline \multicolumn{3}{|l|}{$\mathrm{Hb}>130 \mathrm{~g} / \mathrm{l}(\%$ and $n)$} \\
\hline At week 10 & 28.4 & 59 \\
\hline At week 24 & 1.4 & 3 \\
\hline At week 34 & $6 \cdot 2$ & 13 \\
\hline At delivery & $12 \cdot 0$ & 25 \\
\hline \multicolumn{3}{|l|}{ Newborns } \\
\hline Gender of newborn is male ( $\%$ and $n$ ) & 47.6 & 100 \\
\hline Gestational age (weeks; mean and SD) & $39 \cdot 3$ & 1.4 \\
\hline Birth weight ( $\mathrm{g}$; mean and SD) & 3231.2 & $403 \cdot 7$ \\
\hline Umbilical-cord ferritin ( $\mu \mathrm{g} / \mathrm{l} ;$; mean and SD) & $125 \cdot 2$ & $1 \cdot 8$ \\
\hline
\end{tabular}

regulation cluster (mean 4.6 (SD 2.0)) than children of women with normal levels (mean 5.8 (sD 1.5); $P=0.020$ ). No significant differences were found between these conditions at birth in the bivariate analysis.

\section{Prediction of neonatal behaviour by levels of $\mathrm{Hb}$}

Unadjusted and adjusted multiple linear regression models were performed to assess the effect of haemoconcentration risk during pregnancy on neonatal behaviour (Table 3). In the third trimester, the presence of risk of haemoconcentration was related to a decreased score in the state regulation cluster $(B=-1.273, P=0.006)$ and to a lower alert quality score $(B=-1.848, P=0.006)$. At delivery, the risk of haemoconcentration was also related to a decreased score in the state regulation cluster $(B=-0.796, P=0.021)$ and a poor robustness and endurance supplementary item score ( $B=-0.921, P=0.005)$. No other variables in the analysis were significant.

\section{Discussion}

We carried out a longitudinal study of a population of well-nourished pregnant women to analyse the effect of 
Table 2 Descriptive data of neonatal behaviour depending on $\mathrm{Hb}$ levels of mothers at the end of pregnancy in the sample of healthy and well-nourished pregnant women and their full-term, normal-weight newborns ( $n$ 210), Reus, Spain, 2004-2008

\begin{tabular}{|c|c|c|c|c|c|c|c|c|c|c|c|c|}
\hline & \multicolumn{6}{|c|}{ Third trimester } & \multicolumn{6}{|c|}{ Delivery } \\
\hline & \multicolumn{2}{|c|}{$\begin{array}{c}\text { Anaemia } \\
(\mathrm{Hb}<110 \mathrm{~g} / \mathrm{l}) \\
(n 59)\end{array}$} & \multicolumn{2}{|c|}{$\begin{array}{l}\text { Normal Hb } \\
(\mathrm{Hb}=110- \\
130 \mathrm{~g} / \mathrm{l}) \\
(n 138)\end{array}$} & \multicolumn{2}{|c|}{$\begin{array}{c}\text { Haemoconcentration } \\
\text { risk } \\
(\mathrm{Hb}>130 \mathrm{~g} / \mathrm{l}) \\
(n 13)\end{array}$} & \multicolumn{2}{|c|}{$\begin{array}{c}\text { Anaemia } \\
(\mathrm{Hb}<110 \mathrm{~g} / \mathrm{l}) \\
(n 45)\end{array}$} & \multicolumn{2}{|c|}{$\begin{array}{c}\text { Normal } \mathrm{Hb} \\
(\mathrm{Hb}=110- \\
130 \mathrm{~g} / \mathrm{l}) \\
(n 140)\end{array}$} & \multicolumn{2}{|c|}{$\begin{array}{c}\text { Haemoconcentratior } \\
\text { risk } \\
(\mathrm{Hb}>130 \mathrm{~g} / \mathrm{l}) \\
(n 25)\end{array}$} \\
\hline & Mean & $\mathrm{SD}$ & Mean & $\mathrm{SD}$ & Mean & $\mathrm{SD}$ & Mean & SD & Mean & SD & Mean & SD \\
\hline \multicolumn{13}{|l|}{ NBAS clusters } \\
\hline Habituation & $7 \cdot 8$ & 1.2 & 7.5 & 1.5 & 7.6 & 1.1 & 7.4 & 1.7 & $7 \cdot 7$ & $1 \cdot 2$ & $7 \cdot 3$ & 1.6 \\
\hline Orientation & $5 \cdot 6$ & 1.6 & $5 \cdot 8$ & 1.6 & $5 \cdot 2$ & $1 \cdot 1$ & $5 \cdot 8$ & 1.6 & $5 \cdot 8$ & 1.6 & 5.4 & $2 \cdot 2$ \\
\hline Motor & 5.4 & 0.8 & $5 \cdot 3$ & 1.0 & $5 \cdot 1$ & 0.8 & $5 \cdot 3$ & 0.9 & $5 \cdot 3$ & 0.9 & $5 \cdot 3$ & 1.0 \\
\hline State organization & 3.6 & $1 \cdot 1$ & $3 \cdot 8$ & 0.9 & 3.9 & 0.8 & 3.9 & 0.9 & 3.7 & 1.0 & 3.9 & 0.6 \\
\hline State regulation* & $5 \cdot 8$ & 1.4 & $5 \cdot 8$ & 1.5 & 4.6 & $2 \cdot 0$ & 5.9 & 1.4 & $5 \cdot 8$ & 1.5 & $5 \cdot 1$ & 1.7 \\
\hline Autonomic stability & $7 \cdot 2$ & 0.9 & $7 \cdot 1$ & $1 \cdot 1$ & $6 \cdot 9$ & 1.4 & $7 \cdot 3$ & 0.8 & $7 \cdot 1$ & $1 \cdot 1$ & $7 \cdot 1$ & 1.2 \\
\hline \multicolumn{13}{|l|}{ NBAS supplementary items } \\
\hline Alertness & 5.2 & 2.3 & 5.4 & $2 \cdot 2$ & 3.9 & 2.9 & 5.4 & 2.3 & $5 \cdot 3$ & $2 \cdot 3$ & 4.6 & 2.6 \\
\hline Effort to keep attention & $5 \cdot 8$ & $2 \cdot 1$ & $5 \cdot 7$ & $1 \cdot 8$ & 4.5 & $1 \cdot 8$ & $6 \cdot 0$ & $1 \cdot 8$ & $5 \cdot 7$ & 1.9 & 4.9 & $2 \cdot 0$ \\
\hline Examiner facilitation & 5.4 & $2 \cdot 2$ & $5 \cdot 5$ & $2 \cdot 1$ & 4.5 & $2 \cdot 7$ & $5 \cdot 3$ & $2 \cdot 1$ & $5 \cdot 5$ & $2 \cdot 1$ & $5 \cdot 0$ & 2.5 \\
\hline General irritability & $5 \cdot 6$ & 2.5 & $5 \cdot 7$ & $2 \cdot 2$ & 4.3 & $2 \cdot 7$ & $5 \cdot 8$ & $2 \cdot 3$ & $5 \cdot 7$ & $2 \cdot 3$ & 4.6 & $2 \cdot 3$ \\
\hline Robustness endurance & $5 \cdot 8$ & $2 \cdot 4$ & $5 \cdot 6$ & $2 \cdot 3$ & $4 \cdot 3$ & $2 \cdot 6$ & $5 \cdot 6$ & 2.6 & $5 \cdot 7$ & $2 \cdot 2$ & 4.8 & 2.5 \\
\hline State regulation & $6 \cdot 1$ & 2.5 & $6 \cdot 2$ & $2 \cdot 1$ & $5 \cdot 1$ & $2 \cdot 8$ & $6 \cdot 2$ & $2 \cdot 3$ & $6 \cdot 2$ & $2 \cdot 2$ & 5.8 & 2.4 \\
\hline $\begin{array}{l}\text { Examiner's emotional } \\
\text { response }\end{array}$ & $6 \cdot 1$ & $2 \cdot 3$ & $6 \cdot 1$ & $2 \cdot 1$ & $5 \cdot 1$ & $2 \cdot 4$ & $6 \cdot 1$ & $2 \cdot 1$ & $6 \cdot 0$ & $2 \cdot 2$ & $5 \cdot 7$ & $2 \cdot 3$ \\
\hline
\end{tabular}

NBAS, Neonatal Behavioral Assessment Scale.

${ }^{*}$ Significant $P$ values from Bonferroni post hoc analysis: normal $\mathrm{Hb}$ group $v$. haemoconcentration risk group $(P=0.020)$.

haemoconcentration at the end of pregnancy on neonatal behaviour. Our results show that, as we hypothesized, increased maternal $\mathrm{Hb}$ concentration at the end of the pregnancy is related to poor state regulation behaviour, alertness, robustness and endurance in the neonate.

Previous studies have described relationships between haemoconcentration during pregnancy and the risk of low birth weight, premature delivery and fetal loss ${ }^{(13,21,22,25)}$ and our results show for the first time relationships between pregnancy haemoconcentration and neonatal behaviour as a sign of fetal neurodevelopment.

The healthy pregnant women who participated in the study were Caucasian, with a medium-high socioeconomic level, no known previous obstetric pathology, and typical general and obstetric characteristics in terms of gestational age and previous deliveries. In addition, the women took a moderate Fe supplementation with a mean of $43.9 \mathrm{mg} / \mathrm{d}$ in accordance with the study protocol and the guidelines of the Spanish Ministry of Health and Consumption $^{(43)}$. Fe supplementation is recommended by international organizations in moderate doses $(<60 \mathrm{mg} / \mathrm{d})^{(50)}$ although these moderates doses could be excessive in women who start pregnancy with good Fe stores and with alterations in the haemochromatosis gene (HFE) that increase the intestinal absorption of $\mathrm{Fe}^{(13,51)}$. Mutations in the HFE gene are common in our population, where $47 \%$ of women carry one of the three major mutations ${ }^{(52)}$.

To define groups of $\mathrm{Hb}$ levels and depletion of Fe stores we used the limits established by international organizations ${ }^{(45)}$. SF is considered the best biochemical parameter for monitoring a deficient Fe status in pregnancy in the absence of infection or inflammation because it correctly identifies the women without Fe stores ${ }^{(53)}$. However, a known limitation of $\mathrm{SF}$ is that it also increases with acute or chronic inflammation, malignancy or liver disease. As transferrin saturation does not increase in the presence of inflammation, we used both parameters to detect inconsistent values (high SF and low transferrin saturation) that may hide a possible inflammation with ID, as suggested by some authors ${ }^{(42)}$, and we excluded six women in this situation from the analysis. To define haemoconcentration, we considered high levels of $\mathrm{Hb}$ without taking into account the total plasma volume. This is a limitation because the total plasma volume helps to differentiate the haemodilution status of normal pregnancy from haemoconcentration. However, measuring blood viscosity is laborious and expensive, and therefore, in everyday clinical practice and in many studies, Hb concentration is reported as a measure of haemoconcentration because its relationship with blood viscosity is linear when haematocrit is $<0.5$, which is usually the case in pregnancy ${ }^{(54)}$. Considering all this, we were not able to state that the women with $\mathrm{Hb}>130 \mathrm{~g} / \mathrm{l}$ had haemoconcentration; therefore, we defined them as being at risk of haemoconcentration $^{(24)}$. Our results show that as pregnancy progresses, the percentage of women with depleted Fe stores and anaemia increases. Furthermore, $6.2 \%$ of pregnant women are at risk of haemoconcentration in the third trimester and $12.0 \%$ at delivery. These data are similar to those published by the WHO in its global database on anaemia ${ }^{(1)}$ and also to the results from other European studies ${ }^{(21,25,55)}$, confirming that ID is elevated 
Table 3 Prediction of neonatal behaviour for high levels of $\mathrm{Hb}$ at the end of pregnancy in the sample of healthy and well-nourished pregnant women and their full-term, normal-weight newborns ( $n$ 210), Reus, Spain, 2004-2008

\begin{tabular}{|c|c|c|c|c|}
\hline & Independent variables & $B$ & $P$ value & Model parameters \\
\hline \multicolumn{5}{|l|}{ Third trimester } \\
\hline \multirow[t]{7}{*}{ State regulation cluster } & Unadjusted model & & & \multirow{5}{*}{$R_{c \times 100}^{2}=3 \cdot 6 ; \quad F_{2,203}=3 \cdot 8 ; P=0.024$} \\
\hline & $\mathrm{Hb}$ levels & & & \\
\hline & Normal $v$. haemoconcentration risk & $-1 \cdot 186$ & 0.007 & \\
\hline & Normal $v$. anaemia & -0.023 & 0.924 & \\
\hline & Adjusted model & & & \\
\hline & $\mathrm{Hb}$ levels & & & \multirow{2}{*}{$R_{c \times 100}^{2}=5.0 ; \quad F_{2,189}=3.8 ; P=0.018$} \\
\hline & $\begin{array}{l}\text { Normal } v \text {. haemoconcentration risk } \\
\text { Normal } v \text {. anaemia }\end{array}$ & $\begin{array}{l}-1.273 \\
-0.061\end{array}$ & $\begin{array}{l}0.006 \\
0.809\end{array}$ & \\
\hline \multirow[t]{8}{*}{ Alert quality } & Unadjusted model & & & \multirow{4}{*}{$R_{c \times 100}^{2}=2.7 ; \quad F_{2,203}=2.6 ; P=0.075$} \\
\hline & $\mathrm{Hb}$ levels & & & \\
\hline & Normal $v$. haemoconcentration risk & -1.475 & 0.020 & \\
\hline & Normal $v$. anaemia & $-0 \cdot 317$ & 0.406 & \\
\hline & $\mathrm{Hb}$ levels & & & \multirow{4}{*}{$R_{c \times 100}^{2}=5.3 ; \quad F_{3,189}=3.7 ; P=0.020$} \\
\hline & Normal $v$. haemoconcentration risk & $-1 \cdot 848$ & 0.006 & \\
\hline & Normal $v$. anaemia & -0.376 & 0.320 & \\
\hline & Weight of the newborn (g) & 0.001 & 0.027 & \\
\hline \multicolumn{5}{|l|}{ Delivery } \\
\hline \multirow[t]{7}{*}{ State regulation cluster } & Unadjusted model & & & \\
\hline & $\mathrm{Hb}$ levels & & & \multirow[t]{3}{*}{$R_{c \times 100}^{2}=2.9 ; \quad F_{2,203}=3.0 ; P=0.052$} \\
\hline & $\begin{array}{l}\text { Normal } v \text {. haemoconcentration risk } \\
\text { Normal } v \text {. anaemia }\end{array}$ & $\begin{array}{l}-0.748 \\
-0.048\end{array}$ & $\begin{array}{l}0.023 \\
0.683\end{array}$ & \\
\hline & Adjusted model & & & \\
\hline & Hb levels & & & \multirow{3}{*}{$R_{c \times 100}^{2}=3.4 ; \quad F_{2,189}=2.7 ; P=0.019$} \\
\hline & Normal $v$. haemoconcentration risk & -0.796 & 0.021 & \\
\hline & Normal $v$. anaemia & -0.079 & 0.804 & \\
\hline \multirow[t]{9}{*}{ Robustness and endurance } & Unadjusted model & & & \multirow{5}{*}{$R_{c \times 100}^{2}=3.5 ; \quad F_{2,203}=2.8 ; P=0.062$} \\
\hline & $\mathrm{Hb}$ levels & & & \\
\hline & Normal $v$. haemoconcentration risk & $-1 \cdot 153$ & 0.023 & \\
\hline & Normal $v$. anaemia & -0.667 & $0 \cdot 172$ & \\
\hline & Adjusted model & & & \\
\hline & $\mathrm{Hb}$ levels & & & \multirow{4}{*}{$R_{c \times 100}^{2}=9.2 ; F_{3,189}=5.2 ; P=0.002$} \\
\hline & Normal $v$. haemoconcentration risk & -0.921 & 0.005 & \\
\hline & Normal $v$. anaemia & -0.492 & 0.304 & \\
\hline & Weight of the newborn $(\mathrm{g})$ & 0.001 & 0.002 & \\
\hline
\end{tabular}

Candidate variables in the adjusted models: infant birth weight at delivery (grams); socio-economic status of the family; prenatal exposure to tobacco smoke (no, yes); infant gender (female, male); and maternal prenatal trait anxiety.

even in industrialized countries and that a high percentage of women are at risk of haemoconcentration.

Neonatal behaviour is a phenotypical manifestation of the CNS development and is biologically determined by an interaction between genetics and environmental intrauterine variables ${ }^{(56)}$. In addition to prenatal nutritional status, other environmental variables can affect prenatal neurodevelopment such as maternal prenatal infections, prenatal toxic habits, prenatal emotional states, etc. and the NBAS is a good and sensitive instrument for detecting differences between exposed groups $^{(9,30,31,33,37,57-60)}$. These and other variables affect prenatal neurodevelopment by interacting and even modifying gene expression $^{(26)}$. Therefore, our analysis has taken these aspects into account to disentangle the compound variables that can affect neurodevelopment. Our results show that, after controlling for confounding variables, the risk of haemoconcentration in the third trimester and at delivery is related to poor state regulation cluster scores and infant alert quality and robustness and endurance; that is to say, in general, these infants show more problems with self-regulation, being more excitable and showing more irritability during the examination, and the examiner perceives them to be weaker and to have more attention problems. These results suggest that the third trimester of pregnancy is a critical period for neurodevelopment, when the CNS is more vulnerable to environmental insults possibly due to the speed of several neurological changes, including synapse formation and myelination, and the rapid increase in brain volume (up to $260 \%$ in the third trimester and more than double in the first year of life $)^{(8,39,40)}$.

The poor alertness and self-regulation behaviours shown by infants prenatally exposed to high $\mathrm{Hb}$ concentration levels may indicate that they are more prone to developing the cognitive problems observed by several authors $^{(28,29,61)}$. In this regard, previous studies have shown that lower scores in the NBAS clusters that assess infant irritability were good predictors of verbal and total IQ at 6 years $\mathrm{old}^{(62)}$ and infant psychopathological symptoms ${ }^{(63)}$. The neurobehavioural characteristics shown by neonates of mothers with high $\mathrm{Hb}$ concentrations may be explained in several ways. One explanation 
is that high $\mathrm{Hb}$ concentrations are related to high blood viscosity which can directly reduce the perfusion and oxygenation of the placental and fetal tissues by reducing the blood flow and the efficiency of the nutrient exchange processes, thus decreasing the oxygen and nutrients available to the fetus ${ }^{(20-22)}$. Furthermore, the reduction in nutrient transfer can reduce the availability of the substrate substances needed by the placental hormones that stimulate fetal growth ${ }^{(64)}$ and can increase plasma cortisol in response to hypoxia ${ }^{(65)}$. Other authors suggest that an alternative explanation for the inverse association between $\mathrm{Hb}$ levels and fetal growth (and probably fetal CNS development) may be provided by the direct role of $\mathrm{Hb}$ in nitric oxide regulation and endothelial function. $\mathrm{Hb}$ binds and inactivates nitric oxide (by endothelium-derived smooth-muscle relaxation factor), which leads to vasoconstriction and consequently hypertension and placental ischaemia $^{(66)}$. A recent study shows a direct link between reduced cerebral oxygenation and impaired brain growth in fetuses with congenital heart disease and raises the possibility that in utero brain development could be improved with maternal oxygen therapy ${ }^{(67)}$. On the other hand, among the causes of haemoconcentration are excessive Fe supplementation and pregnancy is a state where there is an increased propensity to produce free radicals, particularly in the presence of $\mathrm{Fe}^{(12)}$, which suggests that both Fe deficiency and excess could produce excessive mitochondrial damage and oxidative stress ${ }^{(68)}$ that could also affect the development of the fetus and its $\mathrm{CNS}^{(67)}$. Several authors have observed the negative influence of high ferritin levels during pregnancy on maternal and infant health ${ }^{(2,16-18,24,69,70)}$ and cognitive development ${ }^{(28)}$, both of which could be due to increased oxidative stress caused by excess Fe. In this regard, oligodendrocyte injury in the developing brain ${ }^{(71)}$ has been related to prenatal oxidative stress and an excessive generation of free radicals in the intra-uterine environment, which increases the risk of neurodevelopment disorders such as schizophrenia in adulthood ${ }^{(57,67)}$. Fe is essential for $\mathrm{Hb}$ synthesis and is important to the CNS in that it contributes to neuronal synapse formation, myelination and the synthesis of certain neurotransmitters ${ }^{(11)}$. However, as in other studies ${ }^{(25,72)}$, we did not observe a negative effect from anaemia. It is likely that the physiological haemodilution that normally occurs in pregnancy can mask these results and that the $\mathrm{Hb}$ cut-off of $<110 \mathrm{~g} / \mathrm{l}$ for anaemia in pregnancy endorsed by the WHO is set too high for the present study population ${ }^{(69)}$.

Our study has some strengths and limitations. While the prospective longitudinal data are methodologically strong, our final sample is modest, and we cannot rule out the possibility of residual confounding. We have included several confounders in the analysis, but it is possible that other confounders affect the relationships studied.

Taking all this information into account, our data allow us to conclude that high levels of $\mathrm{Hb}$ at the end of pregnancy are related to neonatal problems in selfregulation (excitability and irritability), alertness and with a poor robustness in terms of the neonatal behavioural development indicators measured. We suggest and support the practice of tailoring the pattern of Fe supplementation during pregnancy to the individual characteristics of each pregnant woman in order to improve fetal development.

\section{Acknowledgements}

Financial support: This study was financially supported by a grant from the Instituto de Salud Carlos III, Fondo de Investigación Sanitaria, Ministerio de Sanidad y Consumo, Madrid, Spain (grant number PI052462). The funder had no role in the design, analysis or writing of this article. Conflict of interest: The authors declare that they have no conflict of interest. Authorship: N.A. and C.H.-M. are equal contributors. N.A. and C.H.-M. performed the literature search and statistical analyses and drafted the manuscript. N.A., C.H.-M., B.R. and J.C. participated in the fieldwork and in the design of the study. V.A. and J.C. conceived and participated in the design of the study, coordinated the fieldwork and supervised the statistical analyses. All authors contributed to the interpretation of the results and critically revised and approved the manuscript. Ethics of buman subject participation: This longitudinal study was conducted according to the guidelines laid down in the Declaration of Helsinki and all procedures involving pregnant women were approved by the Ethics Committee of the St Joan Hospital in Reus. Women admitted to the study were recruited during their first prenatal care visit (at gestational week $\leq 11$ ) by gynaecologists from the St. Joan University Hospital of Reus and written informed consent was obtained from all of them.

\section{References}

1. World Health Organization (2008) Worldwide Prevalence of Anaemia 1993-2005. WHO Global Database on Anaemia. Geneva: WHO.

2. Aranda N, Ribot B, Garcia E et al. (2011) Pre-pregnancy iron reserves, iron supplementation during pregnancy, and birth weight. Early Hum Dev 87, 791-797.

3. Rasmussen K (2001) Is there a causal relationship between iron deficiency or iron-deficiency anemia and weight at birth, length of gestation and perinatal mortality? J Nutr $\mathbf{1 3 1}$, 2S-2, 590S-601S.

4. Ribot B, Aranda N, Viteri F et al. (2012) Depleted iron stores without anaemia early in pregnancy carries increased risk of lower birthweight even when supplemented daily with moderate iron. Hum Reprod 27, 1260-1266.

5. Allen LH (1993) Iron deficiency anemia increases risk of preterm delivery. Nutr Rev 51, 49-52.

6. Haider BA, Olofin I, Wang M et al. (2013) Anaemia, prenatal iron use, and risk of adverse pregnancy outcomes: systematic review and meta-analysis. BMJ 346, f3443.

7. Oyemade UJ, Cole OJ, Johnson AA et al. (1994) Prenatal predictors of performance on the Brazelton neonatal behavioural assessment scale. J Nutr 124, 6 Suppl, 1000S-1005S. 
8. Thompson RA \& Nelson CA (2001) Developmental science and the media: early brain development. Am Psychol 56, 5-15.

9. Cucó G, Fernandez-Ballart J, Arija V et al. (2005) Effect of $\mathrm{B}_{1^{-}}, \mathrm{B}_{6^{-}}$and iron intake during pregnancy on neonatal behavior. Int J Vitam Nutr Res 75, 320-326.

10. Hernández-Martínez C, Canals J, Aranda N et al. (2011) Effects of iron deficiency on neonatal behavior at different stages of pregnancy. Early Hum Dev 87, 165-169.

11. Georgieff MK \& Rao R (2001) The role of nutrition in cognitive development. In Handbook in Developmental Cognitive Neuroscience, pp. 491-504 [CA Nelson and M Luciana, editors]. Cambridge, MA: MIT Press.

12. Casanueva E \& Viteri FE (2003) Iron and oxidative stress in pregnancy. J Nutr 133, 5 Suppl. 2, 1700S-1708S.

13. Aranda N, Ribot B, Viteri F et al. (2013) Predictors of haemoconcentration at delivery: association with low birth weight. Eur J Nutr 52, 1631-1639.

14. Arija V, Ribot B \& Aranda N (2013) Prevalence of iron deficiency states and risk of haemoconcentration during pregnancy according to initial iron stores and iron supplementation. Public Health Nutr 16, 1371-1378.

15. Aisen P, Cohen G \& Kang JO (1990) Iron toxicosis. Int Rev Exp Pathol 31, 1-46.

16. Casanueva E, Viteri F, Mares-Galindo M et al. (2006) Weekly iron as a safe alternative to daily supplementation for nonanemic pregnant women. Arch Med Res 37, 674-682.

17. Papadopoulou E, Stratakis N, Roumeliotaki T et al. (2013) The effect of high doses of folic acid and iron supplementation in early-to-mid pregnancy on prematurity and fetal growth retardation: the mother-child cohort study in Crete, Greece (Rhea study). Eur J Nutr 52, 326-336.

18. Khambalia AZ, Aimone A, Nagubandi P et al. (2016) High maternal iron status, dietary iron intake and iron supplement use in pregnancy and risk of gestational diabetes mellitus: a prospective study and systematic review. Diabet Med 33, 1211-1221.

19. Sandstrom B (2001) Micronutrient interactions: effects on absorption and bioavailability. Br J Nutr 85, Suppl. 2, S181-S185.

20. Ziaei S, Norrozi M, Faghihzadeh S et al. (2007) A randomised placebo-controlled trial to determine the effect of iron supplementation on pregnancy outcome in pregnant women with haemoglobin $\geq 13.2 \mathrm{~g} / \mathrm{dl}$. BJOG 114, 684-688.

21. Gaillard R, Eilers PH, Yassine S et al. (2014) Risk factors and consequences of maternal anaemia and elevated haemoglobin levels during pregnancy: a population-based prospective cohort study. Paediatr Perinat Epidemiol 28, 213-226.

22. Cordina M, Bhatti S, Fernandez M et al. (2015) Association between maternal haemoglobin at 27-29 weeks gestation and intrauterine growth restriction. Pregnancy Hypertens 5 , 339-345.

23. Steer P, Alam MA, Wadsworth J et al. (1995) Relation between maternal haemoglobin concentration and birth weight in different ethnic groups. BMJ 310, 489-491.

24. Peña-Rosas J \& Viteri F (2009) Effects and safety of preventive oral iron or iron + folic acid supplementation for women during pregnancy. Cochrane Database Syst Rev issue 4, CD004736.

25. Cung TG, Paus AS, Aghbar A et al. (2014) Stillbirths at a hospital in Nablus, 2010: a cohort study. Glob Health Action 7, 25222.

26. Ellison PT (2010) Fetal programming and fetal psychology. Infant Child Dev 19, 6-20.

27. Massaro AN, Rothbaum R \& Aly H (2006) Fetal brain development: the role of maternal nutrition, exposures and behaviors. Eur J Paediatr Neurol 4, 1-9.

28. Tamura T, Goldenberg RL, Hou J et al. (2002) Cord serum ferritin concentrations and mental and psychomotor development of children at five years of age. J Pediatr $\mathbf{1 4 0}$, $165-170$

29. Hanieh S, Ha TT, Simpson JA et al. (2013) The effect of intermittent antenatal iron supplementation on maternal and infant outcomes in rural Viet Nam: a cluster randomised trial. PLoS Med 10, e1001470.

30. Hernández-Martínez C, Arija V, Balaguer A et al. (2008) Do the emotional states of pregnant women affect neonatal behavior? Early Hum Dev 84, 745-750.

31. Hernández-Martínez C, Arija V, Escribano J et al. (2010) Does maternal anxiety affect neonatal behaviour differently in boys and girls? Early Hum Dev 86, 209-211.

32. Conroy S, Pariante CM, Marks MN et al. (2012) Maternal psychopathology and infant development at 18 months: the impact of maternal personality disorder and depression. J Am Acad Child Adolesc Psychiatry 51, 51-61.

33. Koutra K, Chatzi L, Roumeliotaki T et al. (2012) Sociodemographic determinants of infant neurodevelopment at 18 months of age: Mother-Child Cohort (Rhea Study) in Crete, Greece. Infant Behav Dev 35, 48-59.

34. Ding Y, Xu X, Wang Z et al. (2014) The relation of infant attachment to attachment and cognitive and behavioural outcomes in early childhood. Early Hum Dev 90, 459-464.

35. Victora CG, Horta BL, de Mola CL et al. (2015) Association between breastfeeding and intelligence, educational attainment, and income at 30 years of age: a prospective birth cohort study from Brazil. Lancet Glob Health 3, e199-e205.

36. Angulo-Barroso RM, Schapiro L, Liang W et al. (2011) Motor development in 9-month-old infants in relation to cultural differences and iron status. Dev Psychobiol 53, 196-210.

37. Hernández-Martínez C, Arija V, Escribano J et al. (2012) A longitudinal study on the effects of maternal smoking and secondhand smoke exposure during pregnancy on neonatal neurobehavior. Early Hum Dev 88, 403-408.

38. Georgieff MK (2007) Nutrition and the developing brain: nutrient priorities and measurement. Am J Clin Nutr 85, issue 2, 614S-620S.

39. Dobbing JN \& Sands J (1973) Quantitative growth and development of human brain. Arch Dis Child 48, 757-767.

40. Rao R \& Georgieff MK (2000) Early nutrition and brain development. In The Effects of Early Adversity on Neurobehavioral Development. Symposium on Child Psychology, pp. 1-30 [CA Nelson, editor]. Hillsdale, NJ: Erlbaum Associates.

41. Chen X, Scholl TO \& Stein TP (2006) Association of elevated serum ferritin levels and the risk of gestational diabetes mellitus in pregnant women: the Camden study. Diabetes Care 29, 1077-1082.

42. Rambod M, Kovesdy CP \& Kalantar-Zadeh K (2008) Combined high serum ferritin and low iron saturation in hemodialysis patients: the role of inflammation. Clin J Am SOC Nephrol 3, 1691-1701.

43. Ministerio de Sanidad y Consumo (2006) Guía para la Prevención de Defectos Congénitos. Madrid: Ministerio de Sanidad y Consumo; available at http://www.msssi.gob.es/ profesionales/prestacionesSanitarias/publicaciones/Defectos Congenitos.htm

44. Gomez F, Simo JM, Camps J et al. (2000) Evaluation of a particle-enhanced turbidimetric immunoassay for the measurement of ferritin: application to patients participating in an autologous blood transfusion program. Clin Biochem 33, 191-196.

45. World Health Organization (2011) Haemoglobin Concentrations for the Diagnosis of Anaemia and Assessment of Severity. Vitamin and Mineral Nutrition Information System. Geneva: WHO.

46. World Health Organization, United Nations University \& UNICEF (2001) Iron Deficiency Anaemia: Assessment, Prevention, and Control. A Guide for Programme Managers. WHO/NHD/01.3. Geneva: WHO. 
47. Brazelton TB \& Nugent JK (1997) Escala para la Evaluación del Comportamiento Neonatal. Barcelona: Paidós.

48. Spielberger CD, Gorsuch RL \& Lushene RE (1994) STAI Cuestionario de Ansiedad Estado Rasgo [adaptación española: Nicolás Seisdedos Cubero]. Madrid: TEA Ediciones.

49. Hollingshead AB (2011) Four factor index of social status. Yale J Sociol 8, 21-52.

50. World Health Organization (2006) Iron and Folate Supplementation. Standards for Maternal and Neonatal Care. Integrated Management of Pregnancy and Childbirth (IMPAC). Geneva: WHO.

51. Aranda N, Viteri FE, Montserrat C et al. (2010) Effects of C282Y, H63D, and S65C HFE gene mutations, diet, and lifestyle factors on iron status in a general Mediterranean population from Tarragona, Spain. Ann Hematol 89, 767-773.

52. Aranda N, Viteri FE, Fernández-Ballart J et al. (2007) Frequency of the hemochromatosis gene (HFE) $282 \mathrm{C} \rightarrow \mathrm{Y}$, $63 \mathrm{H} \rightarrow \mathrm{D}$, and $65 \mathrm{~S} \rightarrow \mathrm{C}$ mutations in a general Mediterranean population from Tarragona, Spain. Ann Hematol 86, 17-21.

53. Walsh T, O'Broin SD, Cooley S et al. (2011) Laboratory assessment of iron status in pregnancy. Clin Chem Lab Med 49, 1225-1230.

54. Yip R (2000) Significance of an abnormally low or high hemoglobin concentration during pregnancy: special consideration of iron nutrition. Am J Clin Nutr 72, 1 Suppl., 272S-279S.

55. Scholl TO (2005) Iron status during pregnancy: setting the stage for mother and infant. Am J Clin Nutr 81, issue 5 , 1218S-1222S

56. Brazelton TB \& Nugent JK (2011) The Neonatal Behavioral Assessment Scale, 4th ed. Cambridge: Mac Keith Press.

57. Debnath M, Venkatasubramanian G \& Berk M (2015) Fetal programming of schizophrenia: select mechanisms. Neurosci Biobehav Rev 49, 90-104.

58. Kingston D, McDonald S, Austin M et al. (2015) Association between prenatal and postnatal psychological distress and toddler cognitive development: a systematic review. PLOS One 10, e126929.

59. Glover V (2014) Maternal depression, anxiety and stress during pregnancy and child outcome; what needs to be done. Best Pract Res Clin Obstet Gynaecol 28, 25-35.

60. O'Donnell KJ, Glover V, Barker ED et al. (2014) The persisting effect of maternal mood in pregnancy on childhood psychopathology. Dev Psychopathol 26, 393-403.
61. Yang L, Ren AG, Liu JM et al. (2010) Influence of hemoglobin level during early gestation on the development of cognition of pre-school children. Zhonghua Liu Xing Bing Xue Za Zhi 31, 1353-1358.

62. Canals J, Hernández-Martínez C, Esparó G et al. (2011) Neonatal Behavioral Assessment Scale as a predictor of cognitive development and IQ in full-term infants: a 6-year longitudinal study. Acta Paediatr 100, 1331-1337.

63. Canals J, Esparó G \& Fernández-Ballart JD (2006) Neonatal behaviour characteristics and psychological problems at 6 years. Acta Paediatr 95, 1412-1417.

64. Barker DJ (1998) In utero programming of chronic disease. Clin Sci (Lond) 95, 115-128.

65. Iwamoto HS, Murray MA \& Chernausek SD (1992) Effects of acute hypoxemia on insulin-like growth factors and their binding proteins in fetal sheep. Am J Physiol 263, 1151-1156.

66. Kim-Shapiro DB, Schechter AN \& Gladwin MT (2006) Unraveling the reactions of nitric oxide, nitrite, and hemoglobin in physiology and therapeutics. Arterioscler Thromb Vasc Biol 26, 697-705.

67. Sun L, Macgowan CK, Sled JG et al. (2015) Reduced fetal cerebral oxygen consumption is associated with smaller brain size in fetuses with congenital heart disease. Circulation 131, 1313-1323.

68. Walter PB, Knutson MD, Paler-Martinez A et al. (2002) Iron deficiency and iron excess damage mitochondria and mitochondrial DNA in rats. Proc Natl Acad Sci U S A 99 , 2264-2269.

69. Viteri FE, Casanueva E, Tolentino MC et al. (2012) Antenatal iron supplements consumed daily produce oxidative stress in contrast to weekly supplementation in Mexican nonanemic women. Reprod Toxicol 34, 125-132.

70. Peña-Rosas JP, De-Regil LM, Gomez Malave H et al. (2015) Intermittent oral iron supplementation during pregnancy. Cochrane Database Syst Rev issue 10, CD009997.

71. Shen Y, Yu HM, Yuan TM et al. (2007) Intrauterine infection induced oligodendrocyte injury and inducible nitric oxide synthase expression in the developing rat brain. $J$ Perinat Med 35, 203-209.

72. Ribot B, Aranda N, Giralt M et al. (2013) Effect of different doses of iron supplementation during pregnancy on maternal and infant health. Ann Hematol 92, 221-229. 